\title{
LA IRONÍA \\ EN LOS DISCURSOS DE CAMBIO SOCIAL ${ }^{1}$
}

\author{
ESPERANZA MORALES-LÓPEZ \\ Universidad de A Coruña
}

\section{RESUMEN}

En este artículo analizamos el uso de la ironía como recurso persuasivo en dos entrevistas, realizadas respectivamente en 2012 y 2013 a Rafael Correa (presidente de Ecuador) y a la entonces portavoz de la PAH (Plataforma de Afectados por la Hipoteca) Ada Colau (actual alcaldesa de Barcelona). Las dos versan sobre el tema de los desahucios en España. Para el análisis de este tropo desde una perspectiva sistémica, nos basamos en la propuesta constructivista de Hayden White, un filósofo de la historia, quien analiza dicho tropo (junto a la metáfora, metonimia y sinécdoque, siguiendo así la tradición humanista de Vico) en relación con la trama narrativa de una obra histórica y la ideología que se construye. La relación dialéctica que White establece entre el significado histórico de una obra y los recursos discursivos que su autor selecciona para transmitir este significado constituye un ejemplo de propuesta analítica de tipo holístico muy útil para el trabajo de análisis del discurso ideológico. En concreto, la propuesta de White nos ayuda a interrelacionar de manera dialéctica la ironía (una especie de macrofunción) con las diversas formas lingüísticas y discursivas que la construyen (narrativas, estilo directo libre, antítesis léxicas, etc.), y con el contexto en el que estos discursos se llevan a cabo.

Palabras clave: discursos de cambio social, constructivismo, análisis crítico del discurso, retórica constructivista, discursos políticos, entrevistas políticas, discurso retórico, marco cognitivo, conflicto de marcos, Rafael Correa, Ada Colau.

\section{ABSTRACT}

This paper analyses the use of irony as a persuasive resource in two interviews, given by Rafael Correa (president of Ecuador) and the spokesperson of the PAH (The Platform of People affected by Mortgages), Ada Colau (currently mayor of

${ }^{1}$ Esta investigación es parte del proyecto RECDID ("Retórica constructivista: discursos de la identidad (identidades individuales, urbanas y alternativas eco-sociales)"), financiado por el Ministerio español de Industria y Competitividad, y Fondos europeos Feder (FFI2013-40934R; web: <http://cei.udc.es>). 
Barcelona), in 2012 and 2013 respectively. Both interviews refer to the subject of the evictions in Spain. For the analysis of this trope from a systemic perspective, we have based ourselves on the constructivist proposal of Hayden White, a philosopher of history, who analyzes this trope (together with metaphor, metonymy and synecdoche, following the humanist Vico's tradition) in relationship with the plot of a historical work and the ideology which is being constructed. White's dialectic relationship established between the historical meaning of a book and the author's discursive resources selected to convey this meaning is an example of an extremely useful analytical proposal for the analysis of ideological discourses. Specifically, White's proposal helps us to interrelate dialectically irony (a kind of macro-function) with the various linguistic and discursive forms used in the text (narratives, free direct speech, lexical opposites, etc.), and the context within which these discourses take place.

KEYWORDS: discourses of social change, constructivism, critical discourse analysis, constructivist rhetoric, political discourses, political interviews, rhetorical discourse, cognitive frame, conflict of frames, Rafael Correa, Ada Colau.

\section{INTRODUCCIÓN}

En un trabajo anterior (Morales-López, 2011), reflexionábamos sobre el difícil encaje que ha tenido el estudio del discurso ideológico en la disciplina lingüística y cómo poco a poco distintos investigadores han ido ofreciendo alternativas diversas. De entre ellas, destaco las que se plantean de manera rigurosa la interdisciplinariedad y la transdisciplinariedad (más detalles en Morales-López, 2016a, b).

En esta dirección, en nuestro grupo actual de investigación RECDID, venimos trabajando en la confluencia de las siguientes dimensiones:

a) la integración del análisis crítico del discurso con la perspectiva retórico-argumentativa; por mi parte, incluyo además la dimensión etnográfica, como un aspecto fundamental;

b) la dimensión socio-cognitiva del discurso, considerando la cognición humana como un proceso que surge (o emerge) en la interacción, tal como lo conciben, desde el enfoque de la complejidad, los biólogos Maturana y Varela (1990) y Maturana (1996); y

c) el acercamiento a investigadores que desde otras disciplinas humanistas han desarrollado propuestas constructivistas del conocimiento.

En otros trabajos nuestros damos amplia cuenta de cómo llevamos a cabo los dos primeros objetivos (Pujante y Morales-López, 2009, 2013; Pujante, 2011; Montesano Montessori y Morales-López, 2015; Morales-López, 2016a, b, c; Molpeceres Arnáiz, 2016a); en el presente artículo, me deten- 
go en el tercer objetivo, haciendo referencia a un filósofo de la historia, Hayden White, cuyas reflexiones sobre la representación histórica me parecen muy interesantes para aplicarlas al estudio del discurso ideológico.

Desde el punto de vista empírico, este artículo es parte de una investigación más amplia cuyo objetivo más reciente es el análisis crítico de los discursos de cambio social generados tanto por el movimiento social del 15M (Pujante y Morales-López, 2013; y Montesano Montessori y Morales-López, 2015) como por las distintas iniciativas socio-económicas y socio-políticas surgidas y/o dinamizadas tras las acampadas; es lo que denominamos "discursos post-15” (Morales-López, 2016b; Molpeceres Arnáiz, 2016b).

En concreto, aquí me centraré en el análisis de dos fragmentos discursivos que tratan el tema de los desahucios, usando como rasgo discursivo más relevante el tropo de la ironía.

\section{Consideraciones teÓRICO-Metodológicas}

Hayden White, en su libro Metahistoria, cuyo subtítulo es el de La imaginación histórica en la Europa del siglo XIX, parte de la premisa de que la obra histórica es "una estructura verbal en forma de discurso de prosa narrativa que dice ser un modelo, o imagen, de estructuras y procesos pasados con el fin de explicar lo que fueron representándolos" (1973: 14). Por tanto, como otros autores anteriores (Vico, uno de los primeros, y en el siglo xx Foucault, entre otros), White plantea el tema de la representación del realismo histórico como un proceso narrativo de hechos ocurridos en un tiempo anterior, cuyo autor ha interpretado y explicado de manera individual. El resultado parece ser un modelo o imagen (personal) de ese momento histórico.

El método que White utiliza para la investigación histórica es "formalista”, como él lo denomina, a partir de la identificación de los componentes estructurales de los distintos relatos que analiza (en concreto, los de los historiadores Michelet, Ranke, Tocqueville y Burckhardt, y los de los filósofos de la historia Hegel, Marx, Nietzsche y Croce). Los distintos modelos de representación o conceptualización histórica que propusieron no dependen, según White, de la naturaleza de los datos analizados, sino más bien de la consistencia, coherencia y fuerza esclarecedora de sus respectivas visiones del campo histórico. Por ello, no es posible su refutación empírica ni explicativa porque son modelos de narración histórica y, por tanto, su conceptualización histórica parece situarse en el nivel de la configuración discursiva:

Esta [conceptualización histórica] depende, finalmente, de la naturaleza preconceptual y específicamente poética de sus puntos de vista sobre la historia y sus procesos... [Según esto] las obras producidas por esos pen- 
sadores representan concepciones alternativas, y al parecer, mutuamente excluyentes, tanto de los segmentos del proceso histórico como de las tareas del pensamiento histórico... Consideradas como estructuras verbales, las obras que produjeron parecen tener características formales diferentes por completo y disponer de formas fundamentalmente distintas del aparato conceptual utilizado para explicar los mismos conjuntos de datos (White, 1973: 15).

Tal como se desprende de esta cita, White sitúa el fundamento del relato histórico de los autores que analiza no en los hechos ocurridos en sí, sino en las diferentes construcciones verbales, de tipo poético y tropológico, que predominan en dichos textos. De la relación entre el contenido y la forma surgen las distintas concepciones que explican tales hechos. Por tanto, desde su visión, no es posible contraponer lo histórico a lo mítico, siguiendo así también la estela de Vico (1744); la diferencia entre uno y otro tipo de conocimiento reside en el supuesto de que el historiador parte de hechos hallados previamente, mientras que en el discurso mítico o de ficción se trabaja con hechos inventados. Y tras este encuentro con los datos, el historiador tiene que explicarlos en los tres estadios siguientes:

a) explicitar la trama que conllevan (arquetípicamente, el romance, la tragedia, la comedia o la sátira);

b) revelar su argumentación (dando cuenta del sentido y significado por medio de argumentaciones nomológico-deductivas: formistas ${ }^{2}$, organicistas, mecanicistas y contextualistas);

c) mostrar sus implicaciones ideológicas; por este último estadio, White se refiere a un conjunto de prescripciones para tomar posición en el mundo de la praxis social y actuar sobre él para cambiarlo o mantenerlo en su estadio actual; distingue cuatro posiciones ideológicas generales: anarquismo, conservadurismo, radicalismo y liberalismo.

Las implicaciones ideológicas de un determinado texto histórico aportan la dimensión ética de dicha obra, mientras que la trama aporta la percepción estética y la argumentación la operación cognoscitiva:

Un conjunto de sucesos que ha sido tramado como tragedia puede ser explicado "científicamente" (o "realísticamente") apelando a leyes estrictas de determinación causal o presuntas leyes de la libertad humana, según sea el caso. En el primer caso la implicación es que los hombres están sometidos a un destino ineluctable en virtud de su participación en la historia, mientras que en el segundo la implicación es que pueden obrar de tal ma-

${ }^{2}$ La teoría formista apunta a la identificación de las características exclusivas de los objetos que habitan el campo histórico (White, op. cit., 24). 
nera que puedan controlar, o por lo menos afectar, sus destinos. El impulso ideológico de las historias modeladas en estas formas alternativas es casi siempre "conservador" o "radical", respectivamente. No es necesario que estas implicaciones estén expuestas de manera formal, sino que serán identificables por el tono o la actitud en que están expresadas la resolución del drama y la epifanía de la ley que manifiesta... El modo mecanicista de explicación es utilizado [por ejemplo] por Spengler para justificar el tono o la actitud de historias tramadas como tragedias, pero de manera que provoca implicaciones ideológicas que son socialmente acomodaticias. En Marx, sin embargo, una estrategia de explicación mecanicista sirve para sancionar un relato trágico de la historia que es de tono heroico y militante. Las diferencias son exactamente similares a las que distinguen las tragedias de Eurípides de las de Sófocles o, para tomar el caso de un solo escritor, la tragedia del Rey Lear de la de Hamlet (White, 1973: 37).

La combinación de estos tres niveles, modos de tramar, de argumentación y de implicación ideológica, no puede hacerse de manera indiscriminada si lo que se quiere es proporcionar una visión coherente del campo histórico. En opinión de White (1973: 39ss.), la base de la coherencia es de naturaleza poética y lingüística. En este sentido, el historiador actúa como un gramático distinguiendo primeramente los elementos léxicos, gramaticales y semánticos que configuran el nivel figurativo o poético (es decir, el nivel profundo de la imaginación histórica, según el autor), como paso previo a la explicación y representación de los hechos que después ofrecerá en su narración. Este protocolo lingüístico puede realizarse a partir de los cuatro tropos básicos del lenguaje poético, ya señalados por Vico (1744: § 404-408): metáfora, metonimia, sinécdoque e ironía.

La metáfora consiste en una identificación basada en la semejanza: por ejemplo, "mi amor, una rosa" afirma la adecuación de la rosa como representación del ser amado, como figura o símbolo de las cualidades atribuidas a esta persona (una relación objeto-objeto). La metonimia es reduccionista porque parte de la relación de contigüidad de una parte con otra parte de un todo ("tomarse una copa"). La función de la sinécdoque es integrativa (tal es el caso de la expresión "es todo corazón”) porque, aunque parte, como la metonimia, de una relación parte-parte, la parte se integra en un todo que es cualitativamente diferente de la suma de las partes y del cual las partes no son sino réplicas micro-cósmicas; en el ejemplo, el término "corazón" no designa simplemente una parte del cuerpo, sino una cualidad característica de todo el individuo -puede consultarse Pujante (2003: 119-223) acerca de la dificultad de la distinción entre estos dos últimos tropos)-.

Finalmente, la ironía es, según White, esencialmente negativa, en cuanto presupone un punto de vista "realista", y no figurativo, sobre los hechos que narra; de esta forma, la ironía representa un estado de conciencia de 
quien ha llegado a reconocer la naturaleza problemática del lenguaje. En sus distintas manifestaciones señala la futilidad de toda caracterización lingüística de la realidad tanto como el absurdo de las creencias que parodia; en este sentido, es de tipo dialéctico y autocrítico.

En esta definición encontramos de nuevo el rastro de las ideas de Vico (1744: $\$ 408$ y 498). Según Vico, la ironía solo pudo comenzar en la etapa del pensamiento abstracto (no del poético), porque está ligada, no al conocer, sino a la crítica y al juzgar de las cosas, aspecto que incluso puede relacionarse con lo falso y el enmascaramiento de la verdad. White (1978: 73-74) parece prescindir de este posible sentido negativo de la ironía para circunscribirla al terreno del escepticismo, como una actitud crítica sobre el conocimiento.

Tras este repaso de los tropos básicos que sirven de base al modo de tramar la narrativa histórica y a su ideología, se observa cómo la propuesta de White incluye una evidente dimensión constructivista y sistémica a la vez. Por ello, creemos que puede aportar luz en el trabajo de análisis de los discursos ideológicos; sobre todo si nuestro punto de partida incluye claramente una orientación en esta dirección al basarnos, entre otras perspectivas, en la tradición teórico-metodológica de la etnografía (Morales-López, 2014 y 2016c).

Por último, no queremos pasar por alto la definición de la ironía en la tradición retórico-literaria, por ejemplo la de un autor ya clásico, Lausberg (1960: § 582):

La ironía es la expresión de una cosa mediante una palabra que significa lo contrario de ésta. La ironía es un arma de la parcialidad; el orador está tan convencido de la fuerza de la persuasión de su propia causa así como de la simpatía del público, que utiliza una escala léxica de valores de su adversario, haciendo ver su falsedad mediante el contexto (lingüístico o situacional). La voluntas del orador es, pues, tan fuerte que deshace el tejido de mentiras del adversario y ayuda al triunfo de la verdad....

Esta definición relaciona la ironía con la dimensión interaccional y la discusión argumentativa; el orador utiliza este tropo porque se halla inmerso en una actividad comunicativa de tipo persuasivo, con lo cual tiene que rebatir las posiciones de su adversario. En este sentido, se relacionaría, además, con el tono de la enunciación y el contexto extralingüístico (Lausberg, 1960: § 585; véase también Pujante, 2003: 225-227).

En el ámbito lingüístico, pocos han sido los estudios sobre la ironía. Sperber y Wilson (1981: 562) la consideraban un fenómeno semántico, de mención. En este sentido, precisa Pujante (2003: 227), los distintos tipos de ironía se corresponderían con diferentes modos de referir. En nuestro ámbito cultural, Ruiz Gurillo (2013) analiza la ironía en relación con el humor. 
Procedemos, a continuación, al análisis de los datos, centrados en este tropo. En el apartado final de interpretación de los datos relacionaremos estas definiciones de la ironía con nuestras conclusiones tras el análisis.

\section{ANÁlisis DE LOS DATOS DISCURSIVOS SELECCIONADOS}

En otras publicaciones nuestras sobre el discurso ideológico ya hacíamos referencia al uso de recursos discursivos con una finalidad irónica, con lo cual mostrábamos la recurrencia de esta figura de pensamiento con una finalidad retórico-pragmática. Concretamente, en Morales-López (2012b) dábamos cuenta de cómo el presidente Correa de Ecuador hacía un uso frecuente de la ironía por medio del pseudo-discurso directo para imitar irónicamente a sus oponentes, y con ello deslegitimar sus propuestas. Y en Morales-López (2012c) analizábamos el conflicto ideológico de las empresas de energías renovables en España con las empresas de energías extractivas y señalábamos que el recurso más destacado era la recontextualización de las críticas recibidas por parte de las segundas, transformando irónicamente estas críticas en una macro-estrategia de deslegitimación hacia las renovables; de esta forma, se conseguía, argumentativamente, mostrar que tales críticas eran un absurdo.

En ambos trabajos hacía hincapié en la descripción de los recursos que construían la ironía, pero no en esta figura en sí misma. En el presente trabajo adopto una orientación más sistémica, en la dirección que señala White, con lo que relacionaré el uso de esta figura de pensamiento con los recursos discursivos que la crean, así como con el contexto socio-político.

Desde el punto de vista empírico, he seleccionado varios fragmentos de las siguientes dos entrevistas: la primera, al Presidente Correa por las periodistas Gemma Nierga y Pepa Bueno (en el programa "Hoy por hoy"), coincidiendo con uno de sus viajes a España (el 16 noviembre de 2012); y la segunda, a la entonces activista y portavoz de la Plataforma de Afectados por la Hipoteca (PAH), Ada Colau, por parte del periodista Jordi González, en el programa "El Gran Debate", de Telecinco (el 9 de febrero de 2013). En estos fragmentos el tema gira en torno al drama de los desahucios y la oposición de los poderes políticos a la dación en pago; es decir, la cancelación de la deuda hipotecaria con la entrega de la vivienda en caso de impago por razones humanitarias (pérdida de trabajo, enfermedad grave, etcétera).

Desde la perspectiva etnográfica, un aspecto que resulta crucial es explicitar la relevancia de los datos que se seleccionan para una investigación determinada. En este caso, como ya he indicado, los datos que presento me parecen relevantes porque se conectan con el cambio de marco de significación que supuso el movimiento del $15 \mathrm{M}$ en la interpretación de la políti- 
ca española. Tras dos publicaciones sobre los discursos de las acampadas (analizados en Pujante y Morales-López, 2013; y Montesano Montessori y Morales-López, 2015), mi investigación (así como la de otros compañeros del proyecto) ha continuado con el análisis de distintos "discursos post$15 \mathrm{M}$ ”, con el objetivo de estudiar la continuación de este movimiento y su capacidad para el cambio social; así en Morales-López (2016b) me centro en el análisis del discurso de la Cooperativa integral catalana, una propuesta actual de economía eco-social; y en Molpeceres Arnáiz (2016b) se analiza el discurso de Podemos.

Un tema crucial en los discursos post-15M ha sido el de la campaña "Stop desahucios", realizada por los activistas de la PAH, uno de los grupos sociales más activos mediáticamente en los últimos años y que ha protagonizado, de forma muy organizada, acciones de resistencia ante los desahucios e incluso escraches a responsables políticos y bancarios. Con ello, han visibilizado, a lo largo de todo el territorio español, un problema muy grave de desigualdad social porque los bancos, a diferencia de muchas familias de la clase trabajadora, no han pagado por su responsabilidad en la crisis al no haber permitido los Gobiernos del PSOE ni del PP la dación en pago.

Una de las activistas más conocidas de la PAH ha sido la barcelonesa Ada Colau, sobre todo a partir de su comparecencia en el Congreso de los Diputados (más detalles de este acto en la sección siguiente). Con todo, este tema ha traspasado también nuestras fronteras al haberse cebado este problema con los emigrantes que vinieron a España a trabajar en la primera década del nuevo siglo. Entre ellos, el colectivo de emigrantes ecuatorianos que tuvo que salir de su país tras la bancarrota de su economía en el año 2000 y que, casi una década más tarde, se ha visto afectado por una segunda crisis; por tanto, se trata de un colectivo doblemente afectado por los desmanes del capitalismo neoliberal. Esta es una de las razones también de la relevancia de los distintos viajes que ha realizado el presidente Correa a nuestro país, con presencia mediática constante, incluso para referirse a temas españoles y europeos; estos viajes han coincidido, sobre todo, con elecciones en Ecuador, recibiendo mayoritariamente el voto de este colectivo.

Mostramos, a continuación, el análisis de los datos; primero, el fragmento de la entrevista al presidente Correa y, posteriormente, a la activista y actual alcaldesa de Barcelona, Ada Colau.

\subsection{Entrevista a Rafael Correa}

En el fragmento seleccionado para este trabajo (véase completo en el apéndice) constatamos en primer lugar una antítesis en la construcción ideológica, es decir, un conflicto de dos marcos contrapuestos ("marco" en el sentido de Lakoff, 2004; más detalles en Morales-López, 2014 y 2016b). 
Los que se sitúan en el primer marco tienen, en opinión de Correa, un objetivo concreto: alcanzar "la supremacía del capital sobre los seres humanos" (línea 34); un objetivo que se presenta como un hecho realizado reiteradamente: se ha hecho "siempre" (25), "es lo común" (27), basado en la "costumbre" (67) y en "lo técnico" (69); por tanto, el significado de estas expresiones apunta a la intencionalidad de naturalizar este objetivo por parte de sus autores. Además, otra de sus características es que es un marco que no se ha impuesto por la fuerza, sino a través del control de las mentes de las personas: "se nos ha hecho creer que es lo normal" (26) y "nos han hecho creer que es lo normal" (68). En ambas proposiciones, el agente no aparece explícito (la primera es una construcción impersonal y la segunda incluye un agente indefinido a través de la categoría gramatical de persona en plural); además, la construcción verbal hacer creer es de tipo causativo, con dos agentes: el primero (que puede estar implícito) ha sido la causa de determinadas acciones (realizadas por el segundo agente) que han logrado provocar cambios en la creencia de la gente.

El segundo marco se introduce a partir de la repetición del marcador formal adversativo y de sus correspondientes proposiciones: "pero no es normal" (28) y "pero aquí hay algo más de fondo" (32). En la primera premisa argumentativa se realiza una valoración negativa del primer marco y en la segunda se infiere algún tipo de información oculta a través de la construcción impersonal "hay algo más de fondo"; con la imprecisión de dicha expresión se incumple la máxima de modo, se genera una implicatura conversacional que funciona como expectación de la conclusión argumentativa final en (33)-(34): "esto no tiene razón de ser, esto no es otra cosa que la supremacía del capital sobre los seres humanos" (como ya se ha indicado, el objetivo único del marco antagonista, según Correa).

A partir de este momento, Rafael Correa despliega el tropo de la ironía a través de dos recursos. El primero, una narrativa dialogada en la que reproduce de manera ficticia la interacción entre un representante del banco y un ciudadano o ciudadana que, de buena fe, solicitaba una hipoteca ${ }^{3}$. En esta narrativa, la iniciativa partía del banco ("¿no quiere un préstamo?", 38), quien daba "generosamente” más de lo que la persona necesitaba (41-44), pero cuando llegó la crisis exigió más de lo que éticamente es legítimo: la devolución de la casa y la deuda del préstamo restante; es

${ }^{3}$ En Morales-López (2012b) se puede comprobar cómo el uso de la dialogización ficticia, con fines irónicos, es frecuente en los discursos políticos de Correa. Además, en MoralesLópez (2012a) se aportan datos sobre la situación socio-política de Ecuador, con lo que se puede comprender mejor la propuesta política de este político; otro artículo interesante al respecto es Sousa Santos (2013), quien realiza una crítica sobre algunas de las medidas más polémicas de Correa, situándolas en el contexto de las izquierdas latinoamericanas y comparándolas con las europeas. 
relevante para la construcción de este significado el uso de la forma verbal imperativa ("deme...", 51). Por tanto, el tono irónico se consigue con la dialogización de la historia (el elemento dramático, según Lausberg, 1960: $\S 1174$ ) y el absurdo al que conduce, expresado en forma de hipérbole (53-59): la gente se queda sin casa y el capital (la clase poderosa) no asume ningún riesgo. El resultado es una ironía "contra personas extrañas" (en este caso, los bancos, como institución), golpeándolas así con dichas palabras (Pujante, 2003: 226-227).

En contraposición a esta historia, Correa presenta la forma como se resuelve este conflicto en el marco que él defiende: "Cuando, hasta éticamente, el riesgo debe recaer sobre el capital y no sobre los seres humanos" (63-66). El uso de la perífrasis modal de tipo deóntico (debe recaer) evidencia la regulación ética a la que estaría sometida la banca en el nuevo marco, frente a la arbitrariedad del otro.

El segundo recurso se lleva a cabo por medio de expresiones que conducen de nuevo al absurdo (84-99). Comienza la ironía con la repetición de una estructura superlativa: "y lo peor es que... vamos a llegar al peor de los mundos”. La exageración o hipérbole a la que nos lleva se refuerza con varias estructuras paralelísticas: una bimembre "por la ambición del capital financiero, por querer hacer caer todo el peso de la crisis...” en (85-86), y otra trimembre "para la familia, para los ciudadanos y para los propios banqueros" en (90-93). La estructura de foco proposicional que sigue en (94-99): “¿Por qué? Porque...” completa la ironía con una premisa argumentativa de tipo causal, expresada a modo de juego de palabras: "familias que necesitan casas, sin casas, y con banqueros, que no necesitan casas, repletos de casas". Esta antítesis semántica revela el callejón sin salida del capitalismo y su ambición sin límites.

\subsection{Entrevista a Ada Colau}

El fragmento que hemos elegido de la entrevista a Ada Colau comienza con la pregunta del periodista sobre la calificación de "criminales" que ella había realizado a un representante de la banca y por extensión a toda la banca (remitimos también al apéndice). El hecho ocurrió, en el Parlamento español, en la comparecencia de esta activista para defender una Iniciativa Legislativa Popular, promovida por la PAH, en favor de la dación en pago (el 5 febrero de 2013); el mencionado representante de la banca intervino en contra de esta iniciativa; al final, esta no prosperó por el rechazo del Partido Popular, entonces en el poder ${ }^{4}$.

\footnotetext{
${ }^{4}$ Más detalles en <https://es.wikipedia.org/wiki/Ada_Colau>; sobre su trayectoria política más actual: <http://ccaa.elpais.com/ccaa/2015/12/12/catalunya/1449951209_009306.html>.
} 
En el diálogo, el periodista pregunta a Ada Colau por qué no se retracta de haber usado un calificativo tan duro como el de "criminales". En su respuesta, Colau comienza a utilizar la ironía cuando realiza una ruptura de las expectativas comunicativas (lo esperado en estos casos sería algo semejante a una disculpa). En su lugar, realiza una enumeración de otros calificativos, igual de negativos al anterior, para referirse a la actitud de la banca en el tema de los desahucios y su oposición a la dación en pago, incluso cuando se estaban produciendo suicidios de algunas personas implicadas (uno de ellos un día antes de la entrevista): "Podríamos hablar de criminales, cínicos, mentirosos, asesinos después de hechos como los de ayer, estafadores" (12-17). Esta enumeración podría considerarse una amplificación, con el objetivo de conseguir una intensificación de lo afirmado (Pujante, 2003: 127). Concluye dicha enumeración con una premisa argumentativa basada en la aportación de pruebas externas al discurso, con las que, en su opinión, la PAH podía probar tales acusaciones (18-19).

En la conclusión final de su respuesta (20-38), de la misma forma que lo había hecho Correa, Ada Colau contrapone los dos marcos en conflicto: el del capitalismo, situado esta vez en el Parlamento español, que ha resultado estar a favor de los intereses de la banca; y el que ellos defienden, en favor de la gente común y de sus problemas reales. El contraste (para la opinión pública) se produce cuando el activismo logra acceder al Parlamento y se hace evidente el contraste entre ambos marcos ideológicos: "por qué no se oyen más verdades y más coherencia en los lugares que se suponen que deben ser de máxima representación del conjunto de la ciudadanía como puede ser el Congreso... Lo raro es que sea tan difícil... llamar a las cosas por su nombre..." (23-33). La pregunta retórica evidencia el conflicto; y con las dos estrategias de generalización que construye ("Lo raro..." y "vamos a tener un problema como país...") consigue situar el problema en el plano ético.

El segundo recurso irónico es la construcción de otra narrativa en la que recurre también, como lo hace Correa, a la dialogización de parte de la trama. Tras la pregunta que le realiza el periodista acerca de la posible responsabilidad de los ciudadanos en la pérdida de las hipotecas, Colau responde reconociendo que la gente desahuciada ya asume su parte al perder la casa, pero quien no lo hace es la otra parte: la administración pública y la banca. Esto prueba la estafa a la que han sometido a la población.

Para justificar discursivamente este argumento, construye, a modo de ilustración, la historia de la burbuja inmobiliaria en España. La ironía comienza a construirse desde el inicio con el uso de los siguientes recursos (líneas 67-87):

1) La estructura típica de una narración de cuento infantil; el verbo en forma impersonal y el artículo indefinido en la presentación de 
los actores y sus necesidades: "había una población que tenía una necesidad básica”.

2) La antítesis léxica entre esta necesidad básica y otras superfluas: vivienda-yates, como prueba de que la ciudadanía buscaba un fin legítimo.

3) La naturalización del proceso de compra de vivienda frente a la opción del alquiler: "todo, absolutamente todo, te llevaba...", "nada te llevaba a hacerlo a través del alquiler"; el uso del lexema verbal llevar a convierte lo que fueron una serie de acciones políticas de los dos principales partidos (PSOE y PP) en un proceso hecho costumbre, una especie de topoi aristotélico (Aristóteles, 1982) o lugar común de la esencia (Perelman y Olbrechts-Tyteca, 1958) de ser español (de ahí su función como estrategia de naturalización).

Esta generalización contrasta con la personalización que hace aludiendo a las ministras de vivienda que animaban a la compra; el efecto irónico en este caso es inferido, ya que lo relevante es que se está refiriendo a las ministras "socialistas", una de ellas Carme Chacón, de Barcelona, como Ada Colau. La narración concluye haciendo responsable al Estado español de dicha estafa por no haber ofrecido otra alternativa a la de la hipoteca, como se ha hecho en otros países europeos.

A partir de (92), la ironía continúa para referirse al papel de los bancos en dicha estafa. El diálogo ficticio que construye entre los bancos y la ciudadanía muestra también, como en la narrativa de Correa, el papel prepotente de los primeros y su abuso de poder con cláusulas abusivas y con la ayuda de otros agentes (notarios y tasadores) a su servicio. El resultado es una historia de corrupción y de abuso generalizado a las clases trabajadoras. En la conclusión final (líneas 132-134), una estructura de foco (en forma de pregunta-respuesta) exagera el contraste entre los dos marcos en los que se sitúan, por un lado, los políticos tradicionales y la banca y, por otro, la ciudadanía y el activismo de la PAH. Así, tras la pregunta “¿por qué hablamos de estafa?”, la respuesta en forma de proposición existencial construye el foco, expresado además con una prosodia marcada: "Es que es tan evidente".

\section{INTERPRETACIÓN Y CONCLUSIONES}

Al inicio del apartado teórico-metodológico señalábamos el carácter ecléctico de nuestra perspectiva debido a nuestro interés, en los últimos años, por los estudios de la complejidad (Capra, 1996; Massip-Bonet, 2013; Capra et al., 2007; Morales-López, 2015 y 2016a; entre otros). Entre los ras- 
gos que me parecen más interesantes de esta perspectiva se encuentra el hecho de que el estudio científico se impregna, como dice la investigadora argentina Najmanovich (2007: 97-99), de dinamismo, de territorios fluidos, de creatividad, aunque también de cierta incertidumbre (porque la elección del método no es independiente ni precede a priori a la experiencia) y de permeabilidad entre las disciplinas. Por ello, el trabajo científico y humanístico post-positivista asume las siguientes premisas:

1) la dialéctica entre la(s) teoría(s) y los datos (datos corporeizados teniendo en cuenta la subjetividad de los actores sociales y su situación contextual), y

2) la interdisciplinariedad (o transdisciplinariedad) en el estudio de un determinado objeto de estudio.

Este carácter interdisciplinario parece ser también el objetivo actual de investigadores de muchas otras disciplinas discursivas. Pongamos, como ejemplo, la propuesta reciente de Doury y Plantin (2015: 10-11), quienes plantean el análisis de la argumentación en relación con las dimensiones semántica e interaccional, siguiendo así la herencia de Bajtín; también señalan la pluralidad teórica como rasgo esencial de su propuesta, aunque, como afirman también, ello no esté exento del riesgo de la dispersión de las nociones y de los métodos. Un caso bastante similar de interdisciplinariedad es el de la Pragmadialéctica de van Eemeren y Grootendorst (2004), en quienes se inspiran Fairclough y Fairclough (2012), en uno de sus trabajos recientes.

La dialéctica entre las teorías y los datos es asimismo un objetivo de mucha parte de la investigación discursiva actual porque, como precisan también Doury y Plantin (2015: 13), "les donnés ne sont pas reçues mais construites, sur les bases de critères qui doivent être explicités"; es decir, los datos no se le presentan sin más al observador, sino que se construyen en función de un principio organizador (véase también sobre este aspecto Charaudeau, 2009).

En el presente trabajo, el "principio organizador" que me ha guiado, como se ha mostrado en el análisis previo, es el de la relación forma-función para explicar la función de la ironía en los fragmentos discursivos seleccionados. Desde la perspectiva humanística de White, la ironía es uno de los macro-tropos que construyen el conocimiento humano, es decir, el significado; pero si nos inspiramos, además, en la tradición de Halliday (1970), podríamos considerarla algo equivalente a las macro-funciones que se proponen desde la perspectiva sistémica (Martin, 2001), aunque estos autores se circunscriben al ámbito de la cohesión discursiva y no al de la coherencia. En el análisis de la ironía que hemos realizado, nuestro obje- 
tivo ha sido mostrar cómo se ha construido su significado a través de distintos recursos lingüísticos y discursivos. Por tanto, hemos completado nuestro objetivo de relacionar las formas o recursos utilizados y sus funciones, sus significados comunicativos (véase también al respecto Werth, 1999).

Con ello, profundizamos en una de las características diferenciadoras de la investigación en análisis del discurso (sea realizado por lingüistas o por especialistas en retórica) frente al trabajo discursivo publicado desde el ámbito de otras disciplinas sociales (Sociología, Ciencia política, etc.). La relación tan estrecha en nuestros análisis entre la forma y su función garantiza la rigurosidad en el análisis (y con ello un poderoso freno al relativismo), y permite mostrar, además, que la "realidad" que emerge del proceso de significación es, más que una "verdad como correspondencia" respecto a la realidad extra-discursiva (el objetivo de la filosofía del lenguaje formal), una "verdad como coherencia" (el objetivo que comienza a desarrollarse con la filosofía del lenguaje ordinario); es decir, una verdad ética y/o estética, como indica White (1978: 122). El resultado es, por último, una verdad "construida", pero coherente con los objetivos comunicativos de los actores sociales y de las expectativas humanas en la vida social.

En los datos analizados hemos observado cómo en ambos casos se ha recurrido a la narrativización de los hechos en el tema de los desahucios por parte de los bancos, incluyendo en dichas narrativas el pseudo-discurso directo con el que imitan el diálogo desigual entre los representantes del banco y las familias desahuciadas; además, es relevante también la utilización de estructuras paralelísticas diversas, de antítesis semánticas y de otras expresiones léxicas que construyen hipérboles; el fin último del uso de todos estos recursos es la construcción de la ironía. Con ello, se provoca el contraste entre el marco de significación activado desde el capitalismo neoliberal y el marco que emerge con las propuestas de Rafael Correa y de Ada Colau.

En la referencia que hemos hecho en la sección 1 a las definiciones de la ironía hemos indicado que para Vico el uso de la ironía había surgido en la historia del pensamiento humano en una etapa más tardía, tras la aparición de la sabiduría poética, más ligada al tropo de la metáfora; en el segundo estadio del conocimiento, el del conocimiento abstracto, apareció la ironía porque coincidía con la época de la crítica y de los juicios sobre las cosas. White (1973: 224-225), en su trabajo analítico sobre los principales filósofos de la historia del siglo XIX, considera que la ironía representa el ocaso de la época de los héroes y de la capacidad de creer en el heroísmo; con lo cual comienza la desmitificación de la historia y el inicio de su fase realista, es decir, la fase en la que se resalta lo humano de la vida y con ello el escepticismo. Desde el punto de vista lingüístico, continúa White, la ironía refleja el cuestionamiento del lenguaje mismo para 
expresar la realidad, por lo cual se tiende al uso de los juegos de palabras, aforismos, expresiones cómicas, etcétera.

La ironía construida en los discursos de Correa y Colau está ligada, como hemos señalado, a un tiempo y a un contexto nuevo de crisis socioeconómica muy profunda: el colapso del capitalismo mundial en su versión más neoliberal, aunque concretada en la situación española. En ambos casos, la ironía se despliega tras la autoridad que les da su propia experiencia. Correa vivió el colapso bancario de su país en el año 2000 y, desde su llegada al poder en 2006, con un partido nuevo denominado "Alianza País”, ha conseguido su estabilización con un programa económico de centro izquierda; por ello, se siente con autoridad para defender en los medios de comunicación españoles a sus compatriotas ecuatorianos; a ello hay que añadir su gran poder de oratoria en los medios de comunicación. Colau, por su parte, se presentaba en ese momento como activista, con la gran fuerza mediática que le daba también su gran capacidad comunicadora y con el respaldo de la excelente organización de su grupo, la PAH, para la lucha pacífica. En ambos casos, no intervienen en nombre propio, sino como portavoces ('representantes institucionales' en el sentido de Goffman, 1981: 145) de grupos socio-políticos concretos.

La ironía en ambos casos es un recurso (estético, como señala White) a través del cual consiguen magnificar y difundir su mensaje a través de los medios de comunicación, con el fin último de conseguir hegemonía política para sus reivindicaciones. Por tanto, ya no estamos hablando del uso de la ironía como actitud escéptica de un determinado intelectual (es el caso de los discursos históricos, analizados por White), sino de la ironía construida por unos agentes sociales, con un fin argumentativo y persuasivo para conseguir sus objetivos políticos. En ambos casos, no solo realizan una crítica del marco ideológico capitalista -es decir, se sienten fuertes para intentar, como dice Lausberg (1960: § 582) "deshacer el tejido de mentiras del adversario”-; sino que además revelan cómo es el mundo desde el que ellos se sitúan. Por tanto, la ironía no está solamente al servicio de la crítica argumentativa de tipo político, sino que es un recurso para el cambio social. Les permite, sobre todo, evidenciar el contraste entre dos construcciones ideológicas: la de la economía capitalista que nos ha conducido al colapso y la del nuevo imaginario que ellos proponen a la ciudadanía. 


\section{BIBLIOGRAFÍA}

ARIstóteles (1982): Tratados de lógica (Órganon) I. Categorías. Tópicos. Sobre las refutaciones sofisticas, Madrid, Gredos.

CAPRA, F. (1996): La trama de la vida. Una nueva perspectiva de los sistemas vivos, Barcelona, Anagrama.

—, Juarrero, A., Sotolongo, P. y van Uden, J. (eds.) (2007): Reframing complexity. Perspectives from the North and South, Mansfield, MA, ISCE Publishing.

Charaudeau, P. (2009): "Dis-moi quell est ton corpus, je te dirai quelle est ta problématique”, Corpus, 8, págs. 37-66.

Doury, M. y Plantin, Chr. (2015): "Une approache langagière et interactionnelle de l'argumentation”, Argumentation et Analyse du Discours, 15, págs. 1-24.

Fairclough, N. y Fairclough, I. (2012): Political discourse analysis. A method for advances students, Londres, Routledge.

Goffman, E. (1981): Forms of talk, Filadelfia, University of Pennsylvania Press.

HallidaY, M. A. K. (1970): "Language structure and language function", en Jonathan J. Webster (ed.), On grammar, Londres, Continuum, 2002, págs. 173-195.

LAKoff, G. (2004): No pienses en un elefante: lenguaje y debate político, Madrid, Editorial Complutense, 2007.

LAusberg, H. (1960): Manual de retórica literaria, 3 vols., Madrid, Gredos, 1967.

Martin, J. R. (2001): “Cohesion and texture”, en D. Schiffrin, D. Tannen, y H. E. Hamilton (eds.) The Handbook of Discourse Analysis, Malden, Mass., Blackwell, págs. 34-53.

MAssip-Bonet, À. (2013): "Language as a complex adaptative system: Towards an integrative linguistics”, en A. Massip-Bonet y A. Bastardas-Boada (eds.), Complexity perspectives on language, communication and society, Berlín \& Heidelberg, Springer-Verlag, págs. 35-60.

Maturana, H. (1996): La realidad: ¿objetiva o construida?, vol. 2, Barcelona/México DF, Anthropos/Universidad Iberoamericana.

- y VAReLA, F. (1990): El árbol del conocimiento. Las bases biológicas del conocimiento humano, Barcelona, Debate, 1999.

MolpeCeres ArnÁIz, S. (2016a): "La apropiación de la ideología ecologista por parte de los discursos de poder en España: un análisis desde la retórica constructivista”, Revista da Sociedade Portuguesa de Retórica, (en prensa).

- (2016b): "Podemos: discurso retórico, Juego de Tronos, redes sociales. Construyendo nuevas identidades políticas", Opción: Revista de Ciencias Humanas y Sociales (en prensa).

Montesano Montessori, N. y Morales-López, E. (2015): "Multimodal narrative as an instrument for social change: reinventing democracy in Spain -the case of 15M", Critical Approaches to Discourse Analysis Across Disciplines (CADAAD, $<$ http://www.cadaad.net/journal>), 7, 2, págs. 200-219. 
Morales-López, E. (2011) "Hacia dónde va el Análisis del Discurso". Tonos Digital, 21 (<http://www.um.es/tonosdigital/znum21/secciones/estudios-21discurso.htm $>)$.

- (2012a): "Discourses of social change in contemporary democracies: The ideological construction of an Ecuadorian women's group based on 'solidarity economy and finance'”, Text and Talk. An interdisciplinary Journal of Language, Discourse and Communication Studies, 32, 3, págs. 329-348.

- (2012b): "El discurso político de Rafael Correa (Presidente de Ecuador)", Tonos Digital, 23 (<http://www.um.es/tonosdigital/znum23/secciones/mono tonos $>$ ).

- (2012c): "Análisis de discursos ideológicos en la empresa: La deslegitimación y la defensa de las energías renovables", FORUM. Qualitative Social Research, 13/3, Art. 20 (<http://www.qualitative-research.net/index.php/fqs/article/ view/1864>).

- (2014): "La reflexión meta-discursiva como función comunicativa en el proceso de construcción de los discursos de cambio social en un grupo de mujeres”, Sociolinguistic Studies, 8, 2, págs. 249-269.

- (2015): "Argumentation, discourse and constructivist approaches: the analysis of discourses of social change", en B. J. Garssen, D. Godden, G. Mitchell y A. F. Snoeck Henkemans (eds.) Proceedings of the $8^{\text {th }}$ International Conference of the International Society for the Study of Argumentation, Ámsterdam, Sic Sat, págs. 873-881.

- (2016a): "Discourse analysis: Constructivist perspective and transdisciplinarity", en A. Bastardas-Boada, À. Massip-Bonet y G. Bel-Enguix (eds.), Applications of complexity theory in language and communication sciences, (en evaluación).

- (2016b): "Frame construction in post-15M discourses", Ars Rhetorica (en evaluación).

- (2016c): "De la perspectiva etnográfica al análisis crítico del discurso: investigación en un grupo de mujeres ecuatorianas", en B. Crespo, I. Moskowich, M. Frías y C. Núñez-Puente (eds.), Queering Women's and Gender Studies: A Multi-disciplinary and Multi-lingual Approach, NewCastle, Cambridge Scholar Press (en prensa).

Najmanovich, D. (2007): "From paradigms to figures of thought", en F. Capra, A. Juarrero, P. Sotolongo y J. van Uden (eds.), Reframing complexity. Perspectives from the North and South, Mansfield, MA, ISCE Publishing, págs. 92-105.

Perelman, Ch. y Olbrechts-Tyteca, L. (1958): Tratado de la argumentación: La Nueva Retórica, Madrid, Gredos, 1989.

Pujante, D. (2003): Manual de Retórica, Madrid, Castalia.

- (2011): "Teoría del discurso retórico aplicada a los nuevos lenguajes. El complejo predominio de la elocutio", Rétor, 1, 2, págs. 186-214.

- y Morales-López, E. (2009): "Los aspectos argumentativos de las respuestas de Rajoy a un grupo de ciudadanos en el programa de Televisión Española Tengo una pregunta para usted", Oralia, 12, págs. 359-392.

- (2013): "Discurso (discurso político), constructivismo y retórica: los eslóganes del 15-M”, Language, Discourse \& Society 2, 2, págs. 32-59 (<http://www.languageand-society.org/journal/issues.html >). 
RuIZ GuRILLO, L. (2013): "Narrative strategies in Buenafuente's humorous monologues", en L. Ruiz Gurillo y M. B. Alvarado Ortega (eds.), Irony and humor. From pragmatics to discourse, Ámsterdam, John Benjamins, págs. 107-140.

Sousa SANTOS, B. DE (2013): “¿Reinventar las izquierdas?”, <http://www.boaventura desousasantos.pt> (consulta: 20-11-2015).

Sperber, DAn y Wilson, D. (1981): "Irony and the use-mention distinction", en S. Davis (ed.), Pragmatics. A reader, Oxford, Oxford University Press, 1991, págs. 550-563,

van Eemeren, F. H. y Grootendorst, R. (2004): A systematic theory of argumentation. The pragma-dialectical approach, Cambridge, Cambridge University Press.

VICO, G. (1744): Ciencia nueva, Madrid, Tecnos, 2006.

WerTh, P. (1999): Text worlds: Representing conceptual space in discourse, Londres, Longman.

WhITE, H. (1973): Metahistoria. La imaginación histórica en la Europa del siglo XIX, México DF, FCE, 2001.

- (1978): Tropics of discourse. Essays in cultural criticism, Baltimore, The John Hopkins University Press. 


\section{APÉNDICE}

\section{Entrevista a Rafael Correa (fragmento)}

1. GN: Oiga presidente,

2. nos gustaría

3. empezar la conversación

4. hablando de un problema

5. que atañe a nuestro país,

6. que preocupa muchísimo a los españoles

7. y, cómo no,

8. preocupa a los miles de ecuatorianos

9. que viven aquí en España,

10. es el grave problema de los desahucios,

11. presidente, $[\ldots]$

12. ¿qué se puede hacer

13. o qué se ha hecho mal,

14. presidente,

15. para que estos miles de españoles,

16. y lo centro ahora en miles de ecuatorianos,

17. que yo tengo números,

18. que dicen que se han producido

19. cuarenta mil desahucios

20. entre la comunidad ecuatoriana

21. y ochenta mil con problemas para pagar la hipoteca?

22. RC: Mire qué bueno

23. que haya aquí jóvenes,

24. porque en base a

25. hacer lo mismo siempre

26. se nos ha hecho creer que es lo normal,

27. tal vez es lo común

28. pero no es normal.

29. Yo- somos muy respetuosos con la soberanía de todo pa-

30. de todo país,

31. por supuesto con el gobierno del presidente Rajoy, ¿no?

32. Pero aquí hay algo más de fondo eh,

33. esto no tiene razón de ser,

34. esto no es otra cosa que la supremacía del capital sobre los seres humanos.

35. Mire lo que ha pasado, 
36. había exceso de liquidez,

37. los bancos mismos llamaban a los clientes:

38. "Oiga, ¿no quiere un préstamo?”.

$39 . \quad$ Valoraban- valoraban la casa,

40. doscientos mil euros.

41. "Tenga, doscientos cincuenta mil

42. para el coche,

43. los enseres",

44. porque sobraba plata,

45.

y del capital financiero especialmente.

Viene la crisis,

48. la casa que ellos mismos valoraron en doscientos mil

49. ahora vale cincuenta mil,

50. de buena fe no se puede pagar.

51. "Deme la casa

52.

y me queda debiendo ciento cincuenta mil".

53. Es decir,

54. las familias,

55. los seres humanos,

56. los ciudadanos,

57. lo principal,

58. $\quad$ se quedan sin casa

59. y con deuda,

60. ¿̇Y qué riesgo cogió el ca-

61. ¿y qué riesgo tomó el capital?

62. ¡Ninguno!

63. Cuando, hasta éticamente,

64. el riesgo debe recaer

65. sobre el capital,

66. no sobre los seres humanos.

67. Y esto, en base a la costumbre,

68. nos han hecho creer que es lo normal,

69. que es lo técnico;

70. poco menos que una ley natural,

71. un determinismo ineludible;

72. $\quad$ y es absolutamente falso;

73. no es otra cosa,

74. esto no demuestra otra cosa que

75. la relación de poder en una sociedad:

76. quién manda,

77. si los ciudadanos

78. o el capital financiero.

79. $\quad$ Y ese es el gran desafío de la humanidad en el siglo veintiuno,

80. porque a nivel global 
81. nos domina el capital

82. y básicamente ese capital financiero.

83. Eso no tiene por qué ser así. [...]

84. Ylo peor es que,

85. por la ambición del capital financiero,

86. por hacer querer- por querer hacer caer

87. todo el peso de la crisis

88. sobre los seres humanos,

89. vamos a llegar al peor de los mundos

90. para la familia,

91. para los ciudadanos

92. y para los mismos banqueros,

93. para las mismas corporaciones.

94. ¿Por qué?

95. Porque vamos a quedarnos

96. con familias que necesitan casas sin casas,

97. y con banqueros,

98. que no necesitan casas,

99. repletos de casas $[\ldots]$.

\section{Entrevista a Ada Colau (fragmento)}

1. P: Me parece muy bien.

2. Ahora explica a los espectadores,

3. para que todo el mundo lo entienda,

4. por qué no solamente no te retractas [de haber llamado "criminal" al vicesecretario de la Asociación Española de la Banca, en la comparecencia de ambos en el Parlamento español]

5. $\quad$ sino que crees

6. que no hay otra palabra para definir

7. el comportamiento de la banca en España.

8. AC: O que me quedé corta

9. $\quad$ y podríamos añadir más.

10. P: O que te quedaste corta al llamarla-

11. al llamar a este colectivo "criminales".

12. AC: Podríamos hablar de criminales,

13. cínicos,

14. mentirosos,

15. asesinos,

16. después de hechos como el de ayer;

17. estafadores,

18. y creo que hay un montón de pruebas

19. $y$ de datos objetivos que avalan estas palabras. 
20.

21.

22.

23.

24.

25 .

26.

27.

28.

29.

30.

31.

32.

33.

34.

35 .

36.

37.

38.

39.

40.

41.

42.

43.

44.

45.

46.

47.

48.

49.

50.

51.

52.

53.

54.

55.

56.

57.

58.

59.

60.

61.

62.

63.

64.

O sea,

si el problema precisamente-

Yo creo que lo que más ha llamado la atención de todo esto, al menos para el conjunto de la ciudadanía,

es por qué no se oyen más verdades

y más coherencia

en los lugares

que se supone que deben ser de máxima representación

del conjunto de la ciudadanía

como puede ser el Congreso [aplausos del público].

Lo raro es que sea-

Lo raro es que sea tan difícil

escuchar-

llamar a las cosas por su nombre;

eso es lo- lo increíble, ¿no?

Y- y vamos a tener un problema como país,

no vamos a salir de la crisis

y no vamos a poder hablar de democracia

mientras no podamos señalar a los responsables [...]

P: Habrás oído,

al igual que he oído yo,

y además en este programa,

a personas que dicen $[\ldots]$

¿y no tiene culpa

esa gente que se ha hipotecado la vida

sin, cómo te diría,

sin una base suficientemente sólida?

Cuando alguien gana

mil doscientos euros al mes,

¿por qué pide una hipoteca

a treinta años

si sabe que no la podrá pagar? [...]

AC: Pero es que

nadie ha rehuido eso;

nosotros siempre hemos asumido la corresponsabilidad,

quien no la está asumiendo es la otra parte, ¿no?

o sea, las entidades financieras,

y sobre todo la administración pública;

o sea, porque las entidades financieras

son directamente responsables de la estafa

y de la gestión ahora cuando ha estallado la burbuja, ¿no?

de este- presión

que hacen a las familias

para que paguen aunque no tengan ni para comer,

etcétera, 


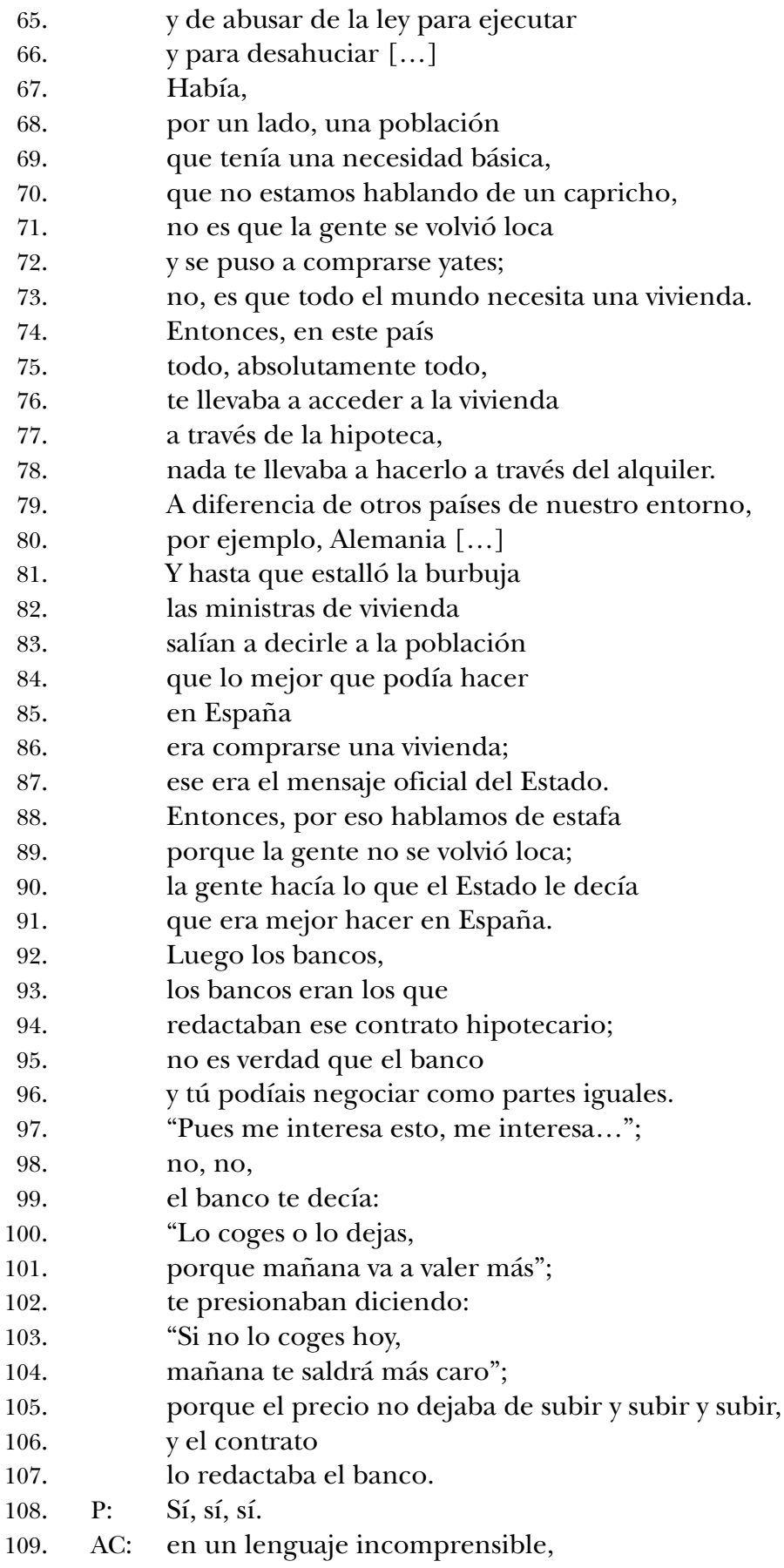


110. P: Sí, sí, sí.

111. AC: repleto de cláusulas abusivas

112. que luego los notarios,

$113 . \quad$ otros que tal,

114. que no hicieron su función;

115. se supone que tienen una función pública

116. de informar a las partes

117. para que sepan

118. lo que están firmando;

$119 . \quad$ pues no hicieron su función.

$120 . \quad$ Las tasadoras,

121. la tasadora te la ponía el banco,

122. no la podías elegir tú

123. y la tasadora

124. ¡oh, casualidad!

125. estaba participada casi siempre por la entidad financiera

126. $\quad$ y ponía el precio

127. que a la entidad financiera

128. le convenía

129. para dar un crédito

130. lo más elevado posible

131. porque así hacían más negocio.

132. Claro, es que suma y sigue,

133. ¿por qué hablamos de estafa?

134. ¡Es que es tan evidente! 